Preprints of the

Max Planck Institute for

Research on Collective Goods

Bonn 2011/4

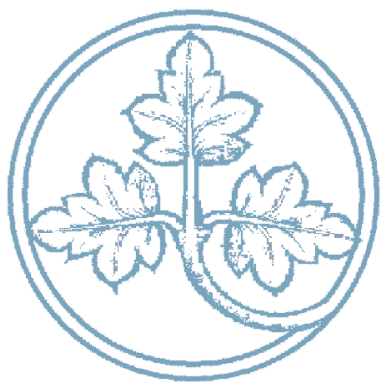

The Role of Consent and Uncertainty in the Formation of Customary International Law

Niels Petersen

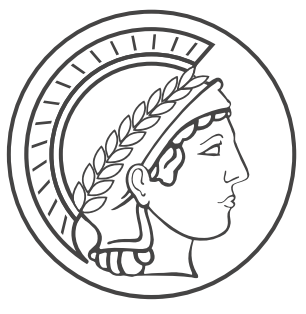




\title{
The Role of Consent and Uncertainty in the Formation of Customary International Law
}

\author{
Niels Petersen
}

February 2011 


\section{Introduction}

The concept of customary law is a fascinating research topic. ${ }^{1}$ There is no other source of international law that has been subject to an equally intensive scholarly debate. Yet, many aspects of the formation of customary law still remain a mystery, ${ }^{2}$ and one has the impression that there is little methodological guidance underlying the identification of customary norms. One of the aspects where this is particularly obvious is the question of how much state practice is needed for the formation of a customary norm. There are two competing schools of thought that stress different characteristics of a customary norm. ${ }^{3}$ Some scholars stress the practice requirement and see customary norms as crystallization points of patterns of state behavior, ${ }^{4}$ while others focus on opinio iuris and perceive customary law as a type of tacit agreement, ${ }^{5}$ which can only bind those who have consented to it. ${ }^{6}$

In practice, however, we see a mixture of both positions, which creates certain tensions. Customary norms can, on the one hand, be formed without the explicit consent of each individual state being necessary. The identification of a customary norm only requires the observation of a general and consistent pattern of state conduct. ${ }^{7}$ States can thus also be bound if they were simply inactive during the phase of the formation of the customary rule or if they were not yet in existence. ${ }^{8}$ On the other hand, every state has the opportunity to opt out of a specific customary norm if it explicitly objects to its formation and can thus be considered as a persistent objector, ${ }^{9}$ which can only be explained from a voluntarist standpoint focusing on consent.

Michael Byers, Custom, Power and the Power of Rules xi (1999).

2 See Martti Koskenniemi, The Pull of the Mainstream, 88 Mich. L. Rev. 1946, 1947 (1990) (qualifying customary law as a theoretical minefield).

3 Martti Koskenniemi, From Apology to Utopia. The Structure of the International Legal Argument 389-397 (2005).

4 See Maurice H. Mendelson, The Formation of Customary International Law, 272 Recueil des Cours 155 (1998); Christoph Engel, An Experimental Contribution to the Theory of Customary (International) Law (Max Planck Institute for Research on Collective Goods, Preprint No. 2010/13, 2010).

5 Some authors even perceive state practice as a dispensable element of the definition of customary law, see Bin Cheng, United Nations Resolutions on Outer Space: “Instant” International Customary Law?, 5 Indian J. Int'1 L. 23 (1965); Andrew T. Guzman, Saving Customary International Law, 27 Mich. J. Int'1 L. 115 (2005); Brian D. Lepard, Customary International Law. A New Theory With Practical Applications 98 (2010).

6 For such a voluntarist position, see, e.g., Godefridus J.H. van Hoof, Rethinking the Sources of International Law 290 (1983); Prosper Weil, Towards Relative Normativity in International Law?, 77 Am. J. Int'1 L. 413 (1983); Karol Wolfke, Custom in Present International Law 87 (1993).

7 Byers, supra note 1, at 130; Christian Tomuschat, International Law: Ensuring the Survival of Mankind on the Eve of a New Century, 281 Recueil des Cours 13, 326 (1999); Patrick Daillier, Mathias Forteau, Alain Pellet \& Nguyen Quoc Dinh, Droit International Public 360 (8th ed. 2009).

8 On the discussion on whether states are bound by customary rules, which were formed before they came into existence, see Georges Abi-Saab, The Newly Independent States and International Law 8-10 (1963); Jonathan I. Charney, The New States and International Legal Order, 118 Recueil des Cours 1 (1966); Michael Schweitzer, Das Völkergewohnheitsrecht Und Seine Geltung Für Neuentstehende Staaten (1969).

9 See Fisheries Case (U.K. v. Nor.) 1951 I.C.J. 116, at 131 (Dec. 18), which is generally regarded as the main authority on the persistent objector principle. The term 'persistent objector' was introduced into the discussion by Ian Brownlie, Principles of Public International Law 8 (1966). However, the principle has not remained without substantial critique, see, e.g., Jonathan I. Charney, The Persistent Objector Rule and the Development of Customary International Law, 56 Brit. Yb. Int'1 L. 1 (1985); Christian Tomuschat, Obligations Arising for States without or against their Will, 241 Recueil des Cours 195, 284-90 (1993); Patrick Dumber- 
According to this interpretation of customary law, there is thus one decisive difference between obligations imposed by treaty and those stemming from custom. Treaty law is an opt-in system. You are only part of the legal regime if you have explicitly consented. Custom, in contrast, is an opt-out system. States are bound by customary rules unless they explicitly object to their formation. Despite this difference, there is one common denominator: In principle, a state cannot be bound by a customary norm against its will. The justification for this rule is the Lotus principle, according to which states can only be bound by a legal norm if they have consented to it. ${ }^{10}$ The Lotus principle thus establishes a freedom of action for states. ${ }^{11}$ Unlike in domestic democratic systems, where individual freedom can be restrained by majority decisions of a representative body, there is no majoritarian decision making mechanism in international law that could restrain the freedom of a state against the will of its representatives.

This contribution analyzes the role of consent in the formation of customary law. It will challenge the assumption that customary norms cannot bind states against their will. Relying on game theory, it will distinguish between different situations and argue that the role of consent differs according to the structure of the social problem that a potential norm is supposed to address. We will approach the topic in two steps. First, there will be a short review of the academic literature on the issue of consent in the formation of customary norms (1.). Second, I will propose a taxonomy of three different situations and propose individual solutions for each of these situations (2.).

\section{The Discussion in the Legal Doctrine}

When we look at state practice, we might observe three different types of state conduct with respect to a specific customary rule. States may affirm the legal rule through their practice, they may abstain from any relevant action, or they may explicitly oppose the formation of the legal rule. If we ask for the amount of consent that is necessary for the emergence of a customary rule, this question can be interpreted in two different ways. First, we can perceive it as a voting rule. If the amount of positive state practice reaches a specific threshold, the emerging customary norm does not only bind all affirming and abstaining states, but even those that are opposed to the formation of the norm. ${ }^{12}$

ry, Incoherent and Ineffective: The Concept of Persistent Objector Revisited, 59 Int'l \& Comp. L. Q. 779 (2010). For a defense and details on this principle see Ted L. Stein, The Approach of the Different Drummer: The Principle of the Persistent Objector in International Law, 26 Harv. Int'l L. J. 457 (1985); Pierre-Marie Dupuy, A propos de l'opposabilité de la coutume générale: enquête brève sur l' objecteur persistant", in Le droit international au service de la paix, de la justice et du développement. Mélanges Michel Virally 257 (1991); Prosper Weil, Le droit international en quête de son identité, 237 Recueil des Cours 9, 189-201 (1992); Wolfke, supra note 6, at 66-67; Mendelson, supra note 4, at 227-244; Olufemi Elias, Persistent Objector, in Max Planck Encyclopedia of Public International Law (Rüdiger Wolfrum ed., 2008).

10 Lotus (Fr. v. Turk.), 1927 P.C.I.J. (ser. A) No. 10, at 18 (Sept. 7).

11 See Albert Bleckmann, Das Souveränitätsprintip im Völkerrecht, 23 Archiv des Völkerrechts 450, 464-468 (1985), who bases his argument on the principle of sovereignty. 
However, considerations about quotas of consent are, secondly, equally important from a perspective according to which customary law is an opt-out system. Even if persistently objecting states are not bound by a customary rule, we have to determine the amount of positive state practice that is necessary to bind at least those states that have abstained from any relevant action. How much explicit consent do we need for a customary rule to emerge? Where is the tipping point at which objections by states do not merely make them persistent objectors, but are an obstacle to the emergence of a norm itself? ${ }^{13}$ Finally, do all states have an equal weight in the formation of customary law, or does the practice of some states count more than the practice of others?

The issue that has so far received the most attention in legal scholarship is the question of whether the practice of all states should be considered equally. Here, we have to distinguish two potential versions of weighting state practice. On the one hand, we have to determine a necessary level of positive practice for a customary rule to emerge. A positive practice of three states is in most cases not sufficient to create a customary norm even if there is no contradicting state practice or protests by other states. In this context, weighting of state practice means that the number of states necessary for positively performing a certain conduct depends on the states that actually do participate. On the other hand, we might consider giving different weight to the practice of different states, even in situations where we observe a contradicting state practice. The weighting would then deviate from the consensus requirement and have the function of a voting rule. ${ }^{14}$

There is a general sense in legal scholarship that the practice of states should not always be weighted equally. Many authors claim, in particular, that greater weight should be given to states that are especially affected. ${ }^{15}$ The idea seems to be intuitive at first glance. If we consider, for instance, a rule of the law of the sea, then it is plausible that the practice of land-locked countries has less of an influence on the formation of a customary rule. In other words: states that have no stakes in the game should, in principle, not be considered. That means that the number of states necessary for the establishment of a state practice depends on the number of states that actually have an interest in this particular area. There are thus different standards for space law than for the law of diplomatic relations.

As far as the weighting concerns the necessary level of positive state practice, it seems plausible or even necessary. It may be highly problematic, however, if we perceive it as a voting mechanism. ${ }^{16}$ Not all cases are as easy as the one of land-locked countries. If states have some interest in a matter and express this interest through a divergent state practice, it will be difficult to determine the states that are especially affected by a certain subject matter. The same is valid for

13 See Elias, supra note 9, at para. 2-6.

14 See Charney, supra note 9, at 19 (arguing in favor of a weighted majority vote).

15 Richard R. Baxter, Treaties and Custom, 129 Recueil des Cours 25, 66 (1970); Wolfke, supra note 6, at 78; Anthoy Clark Arend, Legal Rules and International Society $92-93$ (1999). See also North Sea Continental Shelf (F.R.G. v. Den.), 1969 I.C.J. 3, 42 (Feb. 20), at para. 74 (emphasizing the state practice of specially affected states in its analysis of state practice). The idea is framed slightly differently by Anthony D'Amato, The Concept of Custom in International Law 96-97 (1971), who attributes different weight to the degree of the state's "sophistication" in international law. 
the proposal to give more weight to the practice of large and powerful states. ${ }^{17}$ This may again be a useful tool to determine whether the necessary threshold of positive state practice is met, but it does not work as a voting rule because there might be pronounced and systematic differences of interest between larger and smaller states.

There is no clear-cut rule proposed in the international jurisprudence or in the international legal doctrine of how much consent or how much consistent state practice are necessary for the formation of customary law. ${ }^{18}$ The reason for this vagueness is the structure of the problem. The more clear-cut rules are, the more likely it is that they are either over- or underinclusive. ${ }^{19}$ This is especially the case if the reality they are meant to govern is complex, as a complex reality cannot be grasped by simple rules. If we said that we always needed at least the practice of $\mathrm{x}$ states for the formation of a customary norm, this rule would not take into account that there are areas, such as space law, in which only very few states are able to perform a practice to start with. Furthermore, if we require a simple majority of states, we might not be able to take into account differences in the size and the political importance of a state. Furthermore, there might be a difference between a strong and a weak confirmation of state practice. Do we count them the same way? Or do we have to differentiate? If we differentiate, how much weight do we concede to a weak confirmation of state practice? These illustrations show that the formation of customary law is a complex exercise that needs to leave some flexibility to the lawyer interpreting instances of state practice and assigning legal significance to them.

Therefore, I will not be able to give any clear rules of interpretation in this contribution. I can only give some guidelines. In particular, I want to second guess the consensus principle underlying the theory of customary international law - the dogma that states cannot be bound by a rule of customary international law against their will. ${ }^{20}$ In his recent book, Brian Lepard has advocated the introduction of a majority rule when it comes to the evaluation of contradicting state practice. ${ }^{21}$ In this context, he differentiates between different game-theoretical incentive structures. ${ }^{22}$ According to Lepard, pure coordination problems require a lower level of consensus than a prisoners' dilemma situation. I will try to show in the following that the approach to differentiate according to the structure of the problem is accurate. However, I will propose some crucial modifications with regard to the treatment of the different situations.

17 Michael Byers, Power, Obligation, and Customary International Law, 11 Duke J. Comp. \& Int'1 L. 81, 84 (2001).

18 However, some authors give guidelines. Brian Lepard, for example, requires different levels of consensus depending on how much a customary norm restricts state autonomy: see Lepard, supra note 5, at 158.

19 Koskenniemi, supra note 3, at 591-592.

20 But see also Alain Pellet, The Normative Dilemma: Will and Consent in International Law-Making, 12 Austl. Yb. Int'l L. 22, 37 (1992) (arguing that the principle often only exists in theory because states often do not have the necessary information to protest in time against the formation of a customary norm).

21 Lepard, supra note 5, at 152-153.

22 Id., at 158-61. 


\section{Different standards depending on the structure of the game}

The rationale of the Lotus principle is the idea that every society should be the master of its own fate. It corresponds to the basic liberal principle that "[f]reedom (independence from being constrained by another's choice), insofar as it can coexist with the freedom of every other in accordance with a universal law, is the only original right belonging to every man by virtue of his humanity" 23 , which is one of the cornerstones of the philosophy of the Enlightenment. However, there is one important restriction to Kant's dictum, quoted above. Freedom is not unlimited, but can only be exercised as long as it does not come into conflict with the freedom of other actors of the legal order. There may be situations in which the exercise of one state's freedom restricts the freedom of another legal subject. In such situations, the Lotus principle does not help us to solve the problem in the abstract because we have conflicting claims based on the freedom of action. ${ }^{24}$

I believe that we have to differentiate between three different situations. The first concerns the preservation of common goods. In these situations, contributing to the common good would be the socially optimal solution. However, everyone has an individual incentive not to contribute (a.). Secondly, we will consider norms of coordination. In game-theoretical terms, such situations have multiple equilibria. States thus have to coordinate on one particular equilibrium. However, the choice of the concrete equilibrium does not make any difference from a social point of view (b.). The third situation refers to ethical values, which are - in this contribution understood as rules or principles that do not protect the interests of a particular state, but of third entities, such as individual human beings (c.).

\section{a. Common Goods and the Prisoners' Dilemma}

In the context of this contribution, common goods shall be understood as all goods whose provision or maintenance causes externalities. ${ }^{25}$ The most important common good is a pure public good that is characterized by non-rivalry of consumption and non-excludability of benefits. ${ }^{26}$ Non-rivalry of consumption means that the quality of the good is not affected by the number of people using it. Goods are non-excludable if nobody can be physically excluded from using the good. The classical example is the provision of national defense. The military is not more or less effective if it has to protect more people. Furthermore, people cannot be excluded from the benefit of defense even if they do not want to share it. However, pure public goods do not occur often in practice. But there are a number of impure public goods, which are characterized by partial non-rivalry and/or partial non-excludability. ${ }^{27}$ The most important subcategory for our purposes is common pool resources, whose main characteristic is non-excludability. Examples for com-

23 Immanuel Kant, The Metaphysics of Morals 393 (Mary J. Gregor ed. \& tr., 1996)

24 See Koskenniemi, supra note 3, at 257.

25 For a corresponding definition see Katharina Holzinger, Common Goods, Matrix Games and Institutional Responses, 9 Eur. J. Int'1 Rel. 173, 175 (2003).

26 See Paul A. Samuelson, The Pure Theory of Public Expenditure, 36 Rev. Econ. \& Stat. 387 (1954).

27 See Richard Cornes \& Todd Sandler, The Theory of Externalities, Public Goods, and Club Goods 9 (2d ed. 1996). 
mon pool resources in the international arena are the protection of the global climate or the preservation of fish stocks.

The problem with common goods is that the benefit of the use of these resources is private, while the costs are social. ${ }^{28}$ If we consider clean air as a common good, driving a car yields private benefits for the driver of the car, while the costs - the pollution of the air - have to be borne by everyone and are thus socialized. The incentive structure of the provision or maintenance of common goods typically is that of an n-dimensional prisoners' dilemma. ${ }^{29}$ Individuals have a private incentive to use the resources beyond the level that would be socially optimal.

For an example, let us assume an international society with four states. Each state can either decide to make use of a certain contaminating industry or not to use it. The use of the industry would yield a private benefit of three for that particular state, while yielding social costs of four because of air pollution, which have to be equally borne by all four states. From a global perspective, the best decision would be not to use the industry because a benefit of three and costs of four add up to a negative number. Privately, however, every state has an incentive to use the contaminating industry, because it bears just one unit of the total social costs, so that it has a private benefit of two. The best of all worlds for one state would thus be the one where it is the only state to make use of its contaminating industry, while all the others refuse to do so in order to protect the environment. But even if all other states make use of their contaminating industries, it is still individually rational for the fourth state to make use of its industry as well (see table 1). It has to bear its share of the environmental costs caused by the other three states anyway. Therefore, it will also make use of its own industry and refer part of the costs of the use to the other three states.

Table 1. Payoffs for Each State in Games dealing with Negative Externalities

\begin{tabular}{l|cccc}
\hline \hline $\begin{array}{l}\text { Number of other sta- } \\
\text { tes polluting }\end{array}$ & 0 & 1 & 2 & 3 \\
\hline Pollute & 2 & 1 & 0 & -1 \\
Do not pollute & 0 & -1 & -2 & -3 \\
\hline
\end{tabular}

The most reasonable thing to do in such a situation seems to be to strike an agreement between all states concerned, prohibiting the use of contaminating industries. As the game is played repeatedly in reality, there is high likelihood that states will honor the agreement if they want the

28 Seminally Garrett Hardin, The Tragedy of the Commons, 162 Science 1243 (1968).

29 Russell Hardin, Collective Action as an agreeable n-prisoners' dilemma, 16 Behav. Sci. 472 (1971). As there are many forms of impure public goods, the incentive structure is not necessarily that of an n-dimensional prisoners' dilemma: see Katharina Holzinger, Transnational Common Goods. Strategic Constellations, Collective Action Problems, and Multi-Level Provisions 32 (2008). However, I will limit the analysis in this section to situations involving prisoners' dilemma situations, as this is the most important constellation. 
other parties to the treaty to comply as well. ${ }^{30}$ However, what do we do if there is no agreement? Let us assume that three states abstain from polluting the air with the expectation that the others act likewise, while one state continues to use its contaminating industry. Is this practice sufficient to form a customary norm protecting the clean air? Would this norm be binding for the fourth state, or could the latter be qualified as a persistent objector?

In the world of our model, it seems justified to recognize a customary norm and to extend its scope even to the fourth state although it has not consented. We cannot invoke the sovereignty principle in favor of the fourth state because its behavior has negative external effects. The exercise of its freedom to pollute comes into conflict with the freedom of the other states to enjoy clean air. If we privileged the active freedom of the fourth state against the passive freedom of the other three states, we would privilege freedom of action in general against the passive freedom not to be harmed. However, there seems to be no plausible argument to favor one type of freedom over another. As the potential customary norm supports socially optimal behavior and prevents external effects, we do not have to require consensus for the formation of such a norm. Furthermore, the acceptance of persistent objectors in such situations would exactly contradict the rationale of this construct. While it is supposed to protect the freedom of states, its invocation in our case would exactly promote the violation of the freedom of the majority of states.

In a second step, let us complicate our basic model. Up to now, we have assumed that payoffs are distributed equally across countries. However, this does not seem too realistic. There are some industrialized countries that benefit more from contaminating industries, while there are other countries which are affected more severely by certain environmental harm. We might think, for example, of an island state whose existence is endangered by the rising sea level which is caused by global warming. Moreover, let us assume that for the industrialized state the benefit of the use of its contaminating industries outweighs the environmental costs affecting its territory even if all other states make use of their contaminating industry.

Now, the problem is not just one of finding a social optimum, as it was in the first step, but there are also significant distributive implications. The industrialized state does not have any incentive to enter into an agreement protecting the environment because even if everybody pollutes, the industrialized state is still better off than if it were totally prevented from producing. In contrast, the prohibition of environmental harm is crucial for the survival of the island state. It seems that in this case the arguments that have been presented above carry even more weight. The exercise of its freedom by the industrialized state severely impairs the freedom of the island state so that the industrialized state should be bound by an emerging customary norm even if it has not consented to it.

To complicate the matter further, let us assume in a third step that the private benefits of the industrialized state outweigh the total social costs that are caused by its industrial activity. We could, e.g., think of a conduct that produces a private benefit of five and social costs of four.

30 See George Norman \& Joel P. Trachtman, The Customary International Law Game, 99 Am. J. Int'l L. 541, 553-562 (2005). 
From an economic point of view, it now seems to be more problematic to prohibit the contaminating behavior. We still observe the external effect of the behavior that restricts the freedom of other states. However, the conduct is, in total, socially beneficial. The problem is only that the benefit is not distributed among those who bear the costs. In a world with clear property rights, the industrialized state would go ahead with its contaminating conduct and compensate the other states for their losses. ${ }^{31}$ Because of the complexity of the involved distribution problem, simple majority rules, which provided some guidance in the other situations, do not seem to be the right solution in this case. We either have to recur to consensual solutions or trust courts to find an equitable balance.

Furthermore, we would have a distribution problem of a different kind. Situations in which industrial production outweighs the harm that is caused by industrial pollution require a certain level of technological development. Technologically more developed industries will either be less contaminating or more productive than industries of less developed countries. This brings us to a well-known dilemma of international environmental law: if we impose the same standards on developing countries that we are imposing on developed countries, we might contribute to widening the developmental gap because less developed countries usually have less efficient technology. ${ }^{32}$ One of the rationales of well-designed emission trading systems is to deal with these kinds of distributive issues. ${ }^{33}$ Again, simple majority rules do not provide an adequate answer to the social dilemma.

Finally, we have an epistemological problem. In all of our model worlds, we have so far assumed that we have perfect information. We know the pay-offs of the games and can thus calculate the socially optimal solution. However, this assumption is not realistic. Most often states not only have different interests with regard to certain social problems; they will also disagree with regard to the underlying facts, the costs and benefits of a certain measure. We often do not know what the socially optimal solution of a cooperation problem is. If we knew, we would not need customary international law, but could rely on the judgment of enlightened social engineers. ${ }^{34}$ At least in cases without distributional problems, judges in international courts and tribunals could just impose the socially optimal solution on the parties.

31 This is the conclusion of the Coase theorem, see Ronald H. Coase, The Problem of Social Cost, 3 J. L. \& Econ. 1 (1960).

32 On the issue of differentiated responsibilities for developing countries in international environmental law, see Paul G. Harris, Common But Differentiated Responsibility: The Kyoto Protocol and United States Policy, 7 N.Y.U. Envtl. L.J. 27 (1999); Duncan French, Developing States and International Environmental Law: The Importance of Differentiated Responsibilities, 49 Int'l \& Comp. L. Q. 35 (2000); Graham Mayeda, Where should Johannesburg Take Us? - Ethical and Legal Approaches to Sustainable Development in the Context of International Environmental Law, 15 Colo. J. Int'l Envtl. L. \& Pol'y 29 (2004); Christopher D. Stone, Common But Differentiated Responsibilities in International Law, 98 Am. J. Int'l L. 276 (2004).

33 This is the rationale behind the Clean Development Mechanism of the Kyoto Protocol to the United Nations Framework Convention on Climate Change art. 12, March 16, 1998, 37 ILM 22 (1998) (entered into force Feb. 16, 2005).

34 This is the rationale behind many natural law approaches to international law, see Fernando R. Tesón, The Kantian Theory of International Law, 92 Col. L. Rev. 53 (1992); Antônio Augusto Cançado Trindade, International Law for Humankind: Towards a New Jus Gentium, 316 Recueil des Cours 9 (2005). 
Relying on the opinions of states and state practice is thus an epistemological tool. The more states support a certain rule, the more probable it is that this rule constitutes a socially optimal solution. However, it is not possible to establish a specific quota of support that has to be met for the formation of a customary norm. One indication for the rationality of a specific customary rule may be that it is supported by a majority of states. As the support of the majority is no guarantee for the rationality of a decision, though, it is only an indication for rationality, without already being an expression of it. ${ }^{35}$ Therefore, the more certain we can be about the social optimum of a certain situation, the less consent we need to observe. If we can be fairly certain about the social optimum, the active support of a majority of states will be sufficient to establish a customary norm. However, if there is a lot of uncertainty, we will need to require a higher quota of support.

The same is valid with regard to the question whether we can allow for persistent objectors. In situations with a high amount of certainty, the objection to an emerging customary rule will, in most cases, follow strategic interests. As deviating conduct causes harm to the interests of the whole international community, persistent objection cannot be permitted. When we have identified a rule that protects a common good and we are fairly certain about the social optimum, then this rule is binding upon all states regardless of whether they have objected or not. The situation is different with regard to situations of high uncertainty. Here, we have to take into account that different societies have different risk preferences that have to be respected. Therefore, a persistent objection should, in principle, be possible if a specific state evaluates a certain social dilemma differently than does the majority of the international community.

\section{b. Norms of coordination}

The second category in our taxonomy is norms of coordination. In game-theoretical terms, coordination problems arise if a social problem has different equilibria on which states can focus. In such situations, the states have to focus on one equilibrium. The simplest coordination game is one which offers different options, and in which the states are indifferent with regard to which option to choose (table 2).

Table 2. Simple Coordination Game

\begin{tabular}{c|cc}
\hline \hline & Left & Right \\
\hline Left & 1,1 & $-1,-1$ \\
Right & $-1,-1$ & 1,1 \\
\hline
\end{tabular}

35 There are several reasons why the majority opinion may not be irrational. First, even on the level of governments, irrational decisions may be taken because of a lack of information or competence. Second, sometimes short-term interests may deviate from the long-term interests of a state. If the former, therefore, trumps the latter, states make unsustainable decisions: see Fareed Zakaria, The Future of Freedom. Illiberal Democracy At Home and Abroad 168-169 (2003). Finally, governments may have incentives to make politics for certain particularistic interests to the detriment of the society as a whole: see Mancur Olson, The Logic of Collective Action: Public Goods and the Theory of Groups 127-128 (1965). 
The principal example for this type of situations is certain traffic rules. To an individual, it does not matter whether he drives on the left-hand side or the right-hand side of the street. What matters is that everybody drives on the same side of the street. Some rules of diplomatic communication may have such a character. It is not so important how it is done exactly, but it is important that there is some uniform way of dealing with these issues. The principal function of these norms is thus the protection of expectations. ${ }^{36}$ In most countries, I drive on the right-hand side of the street because I can expect all others to drive there, too.

These situations usually pose little problems for customary norms, as states have an incentive to act in the same way, anyway. If a state acts in a different way, this may be an indication that the costs for the particular behavior might be different than for all other states, e.g. because of a certain, countervailing cultural tradition. If the state is willing to bear the costs of his deviating behavior, international law should not prevent it from doing so. Therefore, in simple coordination situations, there is no reason not to permit persistent objection. Furthermore, if a state clearly protests against the formation of a certain rule, the other states know that the protester will react differently than everybody else. Consequently, if the principal aim of norms of coordination is the protection of expectations, there is no danger that they form false expectations about the conduct of the persistent objector.

However, coordination games can also be more complicated and involve some distributive issues. We can, for example, consider the battle of the sexes game (table 3 ). In the battle of the sexes game, a couple discusses how to spend a Saturday night. While he wants to see a play, she would much rather go to a baseball game. However, both prefer doing something together, rather than spending the evening apart. He is better off accompanying her to the baseball game than spending the evening alone in the theater.

Table 3. Battle of the Sexes Game

\begin{tabular}{c|cc}
\hline \hline & Left & Right \\
\hline Left & 2,1 & 0,0 \\
Right & 0,0 & 1,2 \\
\hline
\end{tabular}

In this game, all parties thus also have an incentive to coordinate on a specific equilibrium. However, they do care which equilibrium to coordinate on, and they have competing interests in this respect. One example from international law is the rules with regard to the delimitation of the continental shelf. Here all parties agree that it is necessary to have a clear rule on this issue in order to have legal certainty. However, their interests may differ with regard to how the rule exactly looks like.

36 See Roger Guesnerie, The Government and Market Expectations, 157 J. Institutional \& Theoretical Econ. 116,124 (2001). 
In the Continental Shelf Case of the International Court of Justice, Denmark, Germany, and the Netherlands were arguing about the rule for the delimitation of their continental shelf. ${ }^{37}$ Denmark and the Netherlands preferred the application of the equidistance principle, according to which all points of the continental shelf are attributed to the country to whose coast they are closest. However, the application of this principle is unfavorable for countries with a concave coastline, such as Germany. Consequently, Germany recognized the general utility of the equidistance principle, but claimed that states with a concave coastline should get a just and equitable share of the continental shelf, which takes into account the proportional length of their coastline. After negotiations failed, the three countries referred the case to the ICJ.

That the countries referred the case to a court already shows that the preferred option was to have legal certainty concerning the shape of the delimitation, regardless of what the actual line would look like. However, they had divergent preferences with regard to the exact shape of the line. In such a case, consent requirements do not seem to be a solution. States prefer having a rule to not having any rule, and the courts do have to take a decision on what such a rule looks like, even though there is no consensus among the parties. Furthermore, simple majority rules do not help us either. The interests of a specific state in the continental shelf example depend on the natural environment of this state. If states with a concave coastline form a minority of all coastal states, then it is likely that their interests will not be taken into account if the majority of states coordinate on the equidistance principle. However, this does not mean that their position should be disregarded because it seems uniquely due to chance whether the majority favors one or the other rule. The application of the majority rule thus only has limited epistemic value in such cases. ${ }^{38}$

Although a majority of states seemed to prefer the equidistance rule in the Continental Shelf case, the court found that this rule was not opposable to Germany. ${ }^{39}$ Hence, how do we have to decide such cases if non liquet is not a viable option? In practice, courts tend to apply principles of bilateral equity in such situations. ${ }^{40}$ In our example, the Court refrained from imposing a concrete delimitation line upon the parties. Instead, it gave the parties some principles of orientation for the negotiation of the delimitation line. It expressly referred to principles of equity in this context ${ }^{41}$ and asked the parties to take all relevant geographic circumstances into account. ${ }^{42}$ If there were still overlapping parts on whose attribution the parties could not agree, these parts should be divided in equal portions. ${ }^{43}$

This determination of customary rules deviates from the classical focus on state practice and opinio iuris. Instead, it refers to equity and justice. The applied standards of equity are, in the end, left to the deciding judge or judicial body. These judges may sometimes be able to refer to

37 North Sea Continental Shelf (F.R.G. v. Den.; F.R.G. v. Neth.), 1969 ICJ Rep. 3 (Feb. 20).

38 On the general epistemic value of the majority rule, see David Estlund, Beyond Fairness and Deliberation: The Epistemic Dimension of Democratic Authority, in Deliberative Democracy 173 (James Bohman \& William Rehg eds., 1997).

39 North Sea Continental Shelf, supra note 37, at $\S 82$.

$40 \quad$ Koskenniemi, supra note 3, at 461-473.

$41 \quad$ North Sea Continental Shelf, supra note 37 , at $\S \S 85,88$.

$42 \quad I d$, at $\S 101$.

$43 \quad I d$. 
general, more abstract principles of international law, but even if such principles exist, the judge will still have a considerable margin of discretion. However, there is probably no better way to deal with these situations. In any case, what is most important to the parties is the existence of a clear rule, while the concrete shape of this rule is only of secondary importance.

\section{c. Ethical values}

States are the primary legislators in international law. They have the power to conclude treaties, and it is their practice that determines the content of customary international law. However, not all norms of international law concern only the direct or indirect interest of states. There are also norms that concern the interests of other legal subjects. The primary example is the norms of international human rights law that are supposed to protect citizens against their state. The problem of these types of norms is that the citizens are not involved in the law-making process. The states themselves do decide about the limits of their power against their citizens. To a certain extent, they can thus conclude a contract to the benefit or the detriment of third persons, the individuals affected by their sovereign power. If a state does not ratify certain human-rights treaties and objects against the formation of customary norms that protect its citizens, the citizens cannot influence the international law-making process.

In the legal order of most states, such contracts to the detriment of third persons are prohibited. In a domestic democracy, where decisions are taken against the interests of certain individuals, these individuals are at least indirectly involved in the decision-making process. However, such a participation of individuals seems practically unfeasible in international law. ${ }^{44}$ There are two possible solutions to the problem that are proposed in the legal literature. On the one hand, scholars recur to natural law concepts. ${ }^{45}$ They assume that it is possible to identify certain universal values that are valid for the whole of humankind and that bind every state of the international community by means of proper reasoning.

However, how do we determine these universal values? Different cultures and societies have different conceptions about what constitutes a good life. Some cultures champion individual rights, while others emphasize the value of the society and thus perceive obligations towards the society as a crucial element of social order. Even if it were possible, in theory, to determine certain universal values, we would need a person or a body that determines these universal values. However, nobody acts behind a veil of ignorance, but has a certain social and cultural imprint that would influence his judgment. Even if we think we know which values are universal, this judgment is certainly in some way influenced by our social and cultural heritage. Therefore, it

44 But see recent accounts in favor of a cosmopolitan democracy: Jürgen Habermas, Kommunikative Rationalität und grenzüberschreitende Politik: eine Replik, in Anarchie der komunikativen Freiheit 406 (Peter Niesen \& Benjamin Herborth eds., 2007); Daniele Archibugi, The Global Commonwealth of Citizens: Toward Cosmopolitan Democracy (2008).

See supra note 34. 
seems impossible to determine natural law-like universal values that form part of customary international law. ${ }^{46}$

On the other hand, we can think of a procedural way of involving the interests of individuals in the process of forming customary international law. One might think of considering only the practice of democratic states as relevant practice for the field of human rights law. ${ }^{47}$ Then citizens would at least indirectly be involved in the process of law-making, as they could, to a certain extent, influence the conduct of their states over democratic processes. However, this approach has one significant conceptual problem as well. It has a predisposition towards democracy. ${ }^{48}$ As only democracies participate in the game, it implies that democracy is the best government form for all states, all cultural environments, and all socio-economic circumstances. However, the political-science literature on democratization theory suggests that the effectiveness of democracy depends on several preconditions - such as a certain level of socio-economic development, the dispersion of power resources, or social and cultural cohesion. ${ }^{49}$

We thus have a tension between the preservation of the cultural autonomy of each individual state and the protection of the citizens against exploitations in the name of cultural exceptionalism. The structure of the problem is a paradoxical one, so that there can be no clear-cut logical answer. However, I want to highlight two points that might help us to deal with this problem in the context of customary international law.

First, conflicts about ethical values are often not so much about the general existence of these values, but more about the relationship between conflicting values. Nobody would deny that people have, in principle, a right to life or a right for the respect of their privacy. However, there may be considerable disagreement about the extent to which these rights can be restricted for social purposes or competing values. Rights can thus rarely be perceived as absolute and unlimited. ${ }^{50}$ Instead, we have to attribute a margin of discretion to states in solving these conflicts. International courts can only control the limits of this margin of discretion, in particular whether there is a legitimate purpose for restricting an individual right and whether there has to be a plausible relation between the pursuance of the aim and the restriction of a human right. ${ }^{51}$

But what about the recognition of the ethical values themselves? Do they only bind those states that have explicitly or implicitly accepted these values, or can a customary norm in this field also be binding on states that oppose the respective norm? Basically, persistent objection cannot be

46 See Amartya Sen, The Idea of Justice (2009), who stresses the impossibility of identifying one global just institutional order.

47 Cf. Lepard, supra note 5, at 155 , who proposes that greater weight should be given to states that comply with fundamental ethical principles.

48 See Martti Koskenniemi, “Intolerant Democracies”: A Reaction, 37 Harv. Int'1 L. J. 231, 232-233 (1996).

49 See Niels Petersen, The Principle of Democratic Teleology in International Law, 34 Brooklyn J. Int'l L. 33, 40-47 (2008) with further references.

50 Yash Ghai, Universalism and Relativism: Human Rights as a Framework for Negotiating Interethnic Claims, 21 Cardozo L. Rev. 1095, 1099 (2000).

51 See Niels Petersen, International Law, Cultural Diversity and Democratic Rule - Beyond the Divide Between Universalism and Relativism, 1 Asian J. Int'l L. 149, 154-56 (2011). 
permitted in cases of an ethical norm. ${ }^{52}$ That would allow certain governments to oppose normative developments to the detriment of their population under the pretext of cultural exceptionalism. Cultural differences can be taken into account by attributing to them a margin of discretion with regard to the solution of conflicts between competing values. Governments can thus not oppose developments without giving reasons, but they have to justify if they want to restrict specific human rights.

\section{Conclusion}

The previous analysis illustrated that we should rethink our approach to consent in the formation of customary international law. There are normative reasons not to stick to one uniform approach, but to distinguish different social situations and different levels of uncertainty. This contribution considered three such situations. First, there are rules with regard to the protection of common goods. In these cases, state consent is a mere epistemological tool. Therefore, states can, in principle, even be bound by a customary rule if they object to their emergence. Second, there are norms concerning cooperation games. In these cases, states can, in principle, only be bound by the norm if they have not objected to the norm. However, there are often cases in which it may be necessary for courts to recur to considerations of bilateral equity. Finally, we identified rules protecting ethical values. Basically, states only have a margin of discretion in balancing competing ethical values, but they cannot individually oppose the emergence of an ethical norm.

The ideas highlighted in this contribution are certainly not exhaustive. There are still many issues that remain to be solved. In some cases, it may, e.g., be fairly clear which kind of social problem we face. In others, the detection of the incentive structure may be more difficult, so that we would have to determine how to proceed in such situations. Furthermore, there may be good reasons to differentiate even more situations in the taxonomy. However, I hope that the contribution helps to draw the attention of the scholarly discussion to aspects that have so far been rather neglected by the debate on customary international law.

52 See also Holning Lau, Rethinking the Persistent Objector Doctrine in International Human Rights Law, 6 Chi. J. Int'l L. 495, 503-05 (2005); Lepard, supra note 5, at 333-336, who both favor considerable exceptions for the application of the persistent objector doctrine in international human rights law. 